\title{
Bioconversion study of dodecanedioic acid from fatty acid and its ester derivatives using Candida tropicalis
}

\author{
Vita Wonoputri, The Arif Setio Nugroho, Jati Putra Maharaja, Johnner Sitompul \\ Department of Chemical Engineering, Institut Teknologi Bandung, Jl. Ganesha No. 10 - Bandung 40132, Indonesia. \\ * Corresponding author: vita@cheitb.id
}

Article history

Received 6 April 2019

Revised 16 June 2019

Accepted 18 September 2019

Published Online 15 April 2020

\begin{abstract}
In this study, the effect of fermentation substrate and its concentration on cell growth and dodecanedioic acid (3DA) production by wild type Candida tropicalis isolated from Ambarella fruit shells in Indonesia was studied. The types of substrate (lauric acid and methyl laurate) and their concentrations $(1,3,5 \mathrm{~g} / \mathrm{L})$ were varied. The addition of $1.67 \%-\mathrm{v} / \mathrm{v}$ of surfactant Tween- 80 increased the solubility of lauric acid and methyl laurate by $13 \%$ and $91 \%$, respectively, as measured by gas chromatography. The added substrates were then utilized by $C$. tropicalis for its growth, whereby the maximum biomass concentration measured by spectrophotometry was attained in methyl laurate system on the last day of experiment (day 5 of bioconversion phase). The cell growth was followed by 3DA production in which the maximum yield was obtained on the fourth day after substrate addition. The maximum 3DA yield of $0.247 \mathrm{~g}-3 \mathrm{DA} / \mathrm{g}$-dissolved substrate was obtained with lauric acid while the maximum 3DA yield for methyl laurate was $0.144 \mathrm{~g}-3 \mathrm{DA} / \mathrm{g}$-dissolved substrate. This research showed potential for 3DA synthesis by using naturally available renewable resources to the fullest instead of using non-renewable petrochemical resources.
\end{abstract}

Keywords: Bioconversion, Candida tropicalis, dodecanedioic acid, lauric acid, methyl laurate

\section{INTRODUCTION}

Dodecanedioic acid, also known as dodecanoic dibasic acid (3DA), is one of important industrial chemicals for various products and mostly used as an intermediate chemical. The uses for 3DA is not only limited as the precursor for nylon production, but also as the precursor for polyamides, resins, adhesives, corrosion inhibitor, cosmetics, emulsifiers, perfume, plastic, and antibiotic productions (Chan \& Kuo, 1997a; Chan \& Kuo, 1997b; Mobley, 1999). Industrial production of 3DA is currently carried out through chemical process by sequential oxidation of butadiene, which is a non-renewable petrochemical resource (Kroha, 2004). Previous study has reported that the chemical process only produces dibasic acids with chain length a multiple of four, making the production of longer chain dibasic acids difficult. The chemical production process also generates dangerous side products, such as NOx (Mobley, 1999). Therefore, one of the imposing challenges for 3DA production is to use renewable resources for sustainable future of the world as well as to overcome the limitations of chemical production of 3DA.

One way to utilize renewable resources as the raw material for 3DA production is through microbial fermentation technology. This production process has several advantages over the conventional chemical production process. For instance, dibasic acid production through fermentation process is safer as it does not produce any hazardous side products and only uses mild operating condition (Campo et al., 2011).

In spite of the numerous advantages, the production of dibasic acid, specifically 3DA through fermentation process is currently still in the research and development stage to find its optimal condition. Many organisms are commonly being utilized as the biocatalyst including at least three strains of Candida, namely $C$. tropicalis, C. Cloacae (Green et al., 2000), and C. viswanathii (Cao et al., 2017). This yeasts family can utilize alkanes or fatty acid into its corresponding fatty alcohol (Huf et al., 2011) via omega ( $\omega$ )-oxidation pathway, whereby the first step of this process is catalyzed by $\omega$-hydroxylase complex composed of a cytochrome P450 monooxygenase (CYP) and a NADPH cytochrome reductase (CPR) (Mobley, 1999). This first step is known as the rate limiting of $\omega$-oxidation pathway. Next, this fatty alcohol is converted to the corresponding aldehyde, followed by aldehyde conversion into carboxy group of fatty acid and dibasic acid, yielding 3DA as one of the products (Bogaert et al., 2011; Huf et al., 2011).

Indonesia holds high potential for fermentation production of 3DA because of the wide availability of renewable fatty acids (originating from natural resources) as the feedstock. However, bioproduction of $3 \mathrm{DA}$ is challenging due to the consumption of 3DA via beta $(\beta)$ oxidation pathway (cell growth) (Bogaert et al., 2011; Huf et al., 2011). Therefore, the utilization of appropriate organism and the development of fermentation technology in 3DA production is important to increase the effectiveness and efficiency of the process, especially in Indonesia.

This research aims to explore the potential of 3DA production in Indonesia using fermentation technology. The focus of this research is to evaluate the bioconversion process of 3DA using a wild strain of $C$. tropicalis, isolated from Indonesia Ambarella fruit shells. The effects of substrate variation, namely lauric acid and methyl laurate and its concentration are evaluated based on the $C$. tropicalis cell growth and 3DA production.

\section{EXPERIMENTAL}

\section{Inoculum preparation and fermentation of 3DA}

C. tropicalis used in this research is a wild strain isolate belonging to Department of Chemical Engineering Institut Teknologi Bandung. The inoculum $(30 \mathrm{ml})$ was prepared by growing $C$. tropicalis in Yeast 
Peptone Dextrose Broth (Sigma-Aldrich) and incubated at $30{ }^{\circ} \mathrm{C}, 150$ rpm for 24 hours.

The 3DA fermentation was performed in two sequential steps, namely the $C$. tropicalis growth phase and the substrate bioconversion phase. The growth phase was initiated by inoculating the $C$. tropicalis inoculum $(30 \mathrm{ml})$ to the fermentation medium (final volume of $300 \mathrm{ml}$ ). The fermentation medium consisted of $5 \mathrm{~g} / \mathrm{L}$ dextrose (Difco Laboratories), $2 \mathrm{~g} / \mathrm{L}\left(\mathrm{NH}_{4}\right)_{2} \mathrm{SO}_{4}$ (Merck KgaA), $2 \mathrm{~g} / \mathrm{L} \mathrm{NH}_{4} \mathrm{NO}_{3}$ (Merck $\mathrm{KgaA}$ ), $1 \mathrm{~g} / \mathrm{L} \mathrm{K}_{2} \mathrm{HPO}_{4}$ (Merck KgaA), $1.5 \mathrm{~g} / \mathrm{L} \mathrm{KH}_{2} \mathrm{PO}_{4}$ (Merck KgaA), $1.5 \mathrm{~g} / \mathrm{L} \mathrm{Na}_{2} \mathrm{HPO}_{4} .2 \mathrm{H}_{2} \mathrm{O}$ (Merck KgaA), $0.2 \mathrm{~g} / \mathrm{L} \mathrm{MgSO}_{4} .7 \mathrm{H}_{2} \mathrm{O}$ (Merck $\mathrm{KgaA}$ ), $0.2 \mathrm{~g} / \mathrm{L} \mathrm{KCl}$ (Merck KgaA), $4 \mathrm{mg} / \mathrm{L} \mathrm{ZnSO}_{4} .7 \mathrm{H}_{2} \mathrm{O}$ (Merck $\mathrm{KgaA}$ ), $4 \mathrm{mg} / \mathrm{L} \mathrm{FeSO}_{4} .7 \mathrm{H}_{2} \mathrm{O}$ (Merck KgaA), and $10 \mathrm{~g} / \mathrm{L}$ yeast extract (Oxoid Ltd). The fermentation broth was incubated at $30{ }^{\circ} \mathrm{C}, 150 \mathrm{rpm}$ for 18 hours. At the end of the growth phase, $10 \mathrm{ml}$ of substrate (either lauric acid, $90 \%$ purity from Laborindo Global Scientific Bandung or methyl laurate, $60 \%$ purity from palm kernel oil purification) dissolved in surfactant (Tween-80, Brataco Chemicals Bandung) was added to the medium to trigger the bioconversion phase. The bioconversion phase was performed at $30^{\circ} \mathrm{C}, 150 \mathrm{rpm}$ for 5 days, where an aliquot of $2 \mathrm{ml}$ was taken daily for analysis. The fermentation $\mathrm{pH}$ was regularly adjusted to $\mathrm{pH} 8$ using $5 \mathrm{M} \mathrm{NaOH}$. A stable $\mathrm{pH}$ of the fermentation broth is important to ensure the desired products are synthesized effectively because $\mathrm{pH}$ has influence on most biosynthesis processes (Show et al., 2015)

\section{Biomass concentration analysis}

Biomass concentration analyses were performed by measuring the optical density at $600 \mathrm{~nm}\left(\mathrm{OD}_{600}\right)$ using spectrophotometry (Thermo Scientific GENESYS 20). After each measurement, the samples were centrifuged at 10,000 rpm for 15 minutes to separate the biomass, which were dried and measured (reported as the dry cell weight). A calibration curve was then plotted based on the absorbance and dry cell weight of each samples.

\section{Lauric acid concentration analysis}

Lauric acid concentration was analyzed following the lauric acid isolation from the fermentation broth. Isolation was performed by esterification of the lauric acid, started by reacting $1 \mathrm{ml}$ of the cell-free samples with $1 \mathrm{ml}$ of $6 \%-\mathrm{v} / \mathrm{v}$ methanolic sulphuric acid. The mixtures were then heated in a waterbath at $90{ }^{\circ} \mathrm{C}$ for 3 hours, followed by cooling to room temperature and reaction with $0.5 \mathrm{ml}$ hexane. The mixtures were homogenized and centrifuged at $5000 \mathrm{rpm}$ for 5 minutes, yielding organic and aqueous phases. Analyses of the organic phase were performed using gas chromatography (DANI Master GC Fast Gas Chromatography System equipped with RTX-5 column). A calibration curve was plotted using various lauric acid standard solutions with the identical analytical method.

\section{Methyl laurate concentration analysis}

Similar as previous procedure, isolation of methyl laurate preceded the concentration analysis. The isolation was performed by adding $1 \mathrm{ml}$ Hexane into $0.5 \mathrm{ml}$ of cell-free fermentation broth. The mixtures were homogenized and centrifuged at $5000 \mathrm{rpm}$ for 5 minutes to separate the organic and aqueous phase. The organic phase was analyzed using gas chromatography. A calibration curve was plotted using various methyl laurate standard solutions with the identical analytical method.

\section{Product (3DA) concentration analysis}

The product concentration analyses were initiated by isolation of 3DA from the fermentation broth by adding $0.1 \mathrm{ml}$ of $6 \mathrm{~N}$ sulphuric acid into $0.1 \mathrm{ml}$ of cell-free fermentation broth to lower the broth $\mathrm{pH}$ to 2. The mixtures were homogenized and reacted with $0.4 \mathrm{ml}$ of diethyl ether. Following the second homogenization, the mixtures were centrifuged at $5000 \mathrm{rpm}$ for 5 minutes, whereby $0.2 \mathrm{ml}$ of the organic phases were reacted with $0.1 \mathrm{ml}$ N,Obis(trimethylsilyl)trifuoroacetamide. The final mixtures were analyzed using gas chromatography. A calibration curve is plotted using various 3DA standard solutions with the identical analytical method.

\section{RESULTS AND DISCUSSION}

As previously mentioned, 3DA fermentation was preceded by $C$. tropicalis growth phase and followed by substrate bioconversion phase. The main purpose of the growth phase was to increase the $C$. tropicalis cell concentration, thereby improving the efficiency of the bioconversion process. The growth phase of C. tropicalis lasted for 18 hours using glucose $(5 \mathrm{~g} / \mathrm{L})$ as the primary carbon source. Utilization of glucose in the growth phase reduced both yeast lag phase and the $\beta$ oxidation activity, subsequently allowing higher 3DA yield (Green, et al. 2000). At the end of the growth phase, simultaneously the start of bioconversion phase (denoted as day 0 of incubation), the glucose concentration dropped to $0.5-1 \mathrm{~g} / \mathrm{L}$ (result not shown), indicating glucose consumption by $C$. tropicalis for growth, as the cell concentration increased to $0.8-1 \mathrm{~g} / \mathrm{L}$ (Figure 1). The substrates (lauric acid or methyl laurate; 1,3 , or $5 \mathrm{~g} / \mathrm{L}$ ) were then added. Based on CAS Database, both substrates used in this study have low solubility in water where the solubilities of lauric acid and methyl laurate in water at 25 ${ }^{\circ} \mathrm{C}$ are $4.81 \mathrm{mg} / \mathrm{L}$ and $7.56 \mathrm{mg} / \mathrm{L}$, respectively. It is known that surfactants can promote the solubility of hydrophobic substances in water (Feng, 2006). For instance, Lee et al. (2017) used Tween-80 to solubilize the substrate for producing 3DA. Chan et al. (1997) showed that the use of Tween-80 resulted in the best yield for the production of 1,13-dicarboxylic acid compared to other surfactants. Thus, $1.67 \%$-v/v of Tween- 80 was added together with the substrates to improve the solubility. Based on Figure 2, the addition barely resulted in any increase of lauric acid solubility, as only $0.13,0.27$, and $0.32 \mathrm{~g} / \mathrm{L}$ were detected in the solution after the addition of 1,3 , and $5 \mathrm{~g} / \mathrm{L}$ of lauric acid, respectively. On the other hand, the additions of 1,3 , and $5 \mathrm{~g} / \mathrm{L}$ of methyl laurate together with the surfactant increase the solubility of the substrate to $0.89 \mathrm{~g} / \mathrm{L}, 1.52 \mathrm{~g} / \mathrm{L}$, and $1.90 \mathrm{~g} / \mathrm{L}$, respectively. Although preliminary experiment showed that the addition of $1.67 \%-\mathrm{v} / \mathrm{v}$ of Tween- 80 was enough to solubilize the substrates in the absence of the cell, $C$. tropicalis was known to be capable of metabolizing Tween-80, causing substrate solubilization in the surfactant to decrease (Slifkin, 2000).
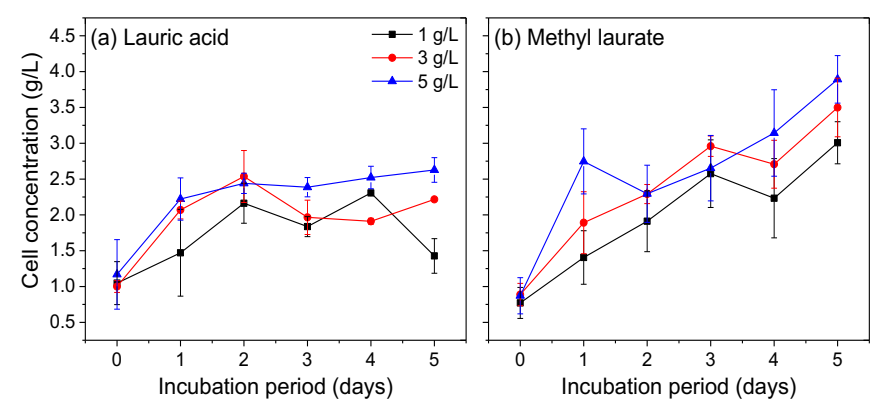

Fig. 1 Cell growth profile during the bioconversion phase following the addition of (a) lauric acid and (b) methyl laurate in varying concentrations. Error bars indicate standard error between replicates $(n=3)$.
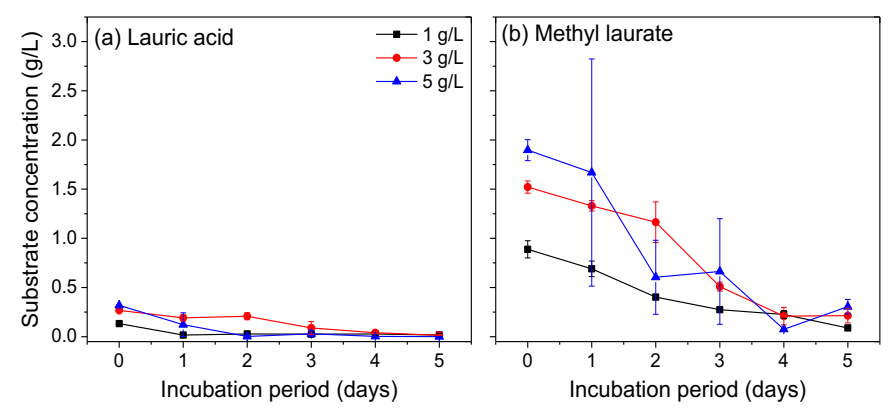

Fig. 2 Substrate concentration profile during bioconversion phase for (A) lauric acid substrate and (B) methyl laurate substrate. Error bars indicate standard error between replicates $(n=2)$. 
During the subsequent bioconversion phase, glucose concentration remains relatively constant (result not shown), while substrates concentration decreases (Figure 2) and cell concentration increases (Figure 1), indicating that C. tropicalis is able to utilize the added substrates as the primary carbon source. Continuous cell growth was observed, with the most significant rise observed on the first day. Similar observation has been reported, whereby the highest growth rate of the C. tropicalis happens at 18-24 hours from the start of the bioconversion phase (Lee et al., 2017). At the end of observation, the maximum biomass obtained in the lauric acid and methyl laurate systems are $2.6 \mathrm{~g} / \mathrm{L}$ and $3.9 \mathrm{~g} / \mathrm{L}$, respectively. Lower final biomass yield was observed in the system that contain lauric acid than methyl laurate due to limited accessible lauric acid caused by its lower solubility as shown previously. Moreover, lauric acid is also known to have inhibitory effect (Kabara, 1984), which can contribute further in here. However, the addition of these carbon sources allow continuous cell growth indicating that the available substrates are mostly used for the $\beta$-oxidation pathway, which is the main metabolism pathway for cell growth. This was caused by the natural characteristic of wild yeast used in the experiment, and also the relatively high glucose concentration that still existed during the bioconversion phase. Another research (Gmünder et al., 1981) found that the presence of glucose during bioconversion phase can cause repression of Cytochrome P450/reductase enzyme, which is a major enzyme involved in bioconversion of substrate into dibasic acid/3DA.

The reduction in substrate concentration and the rising of cell concentration were followed by detection of 3DA from the systems, both when lauric acid and methyl laurate were used as the substrates (Figure 3). Higher overall 3DA production is observed in the presence of methyl laurate as the substrate, possibly caused by higher solubility of methyl laurate in the system (Figure 2). The 3DA concentration detected from the system increased from the first day up to the fourth day, reaching maximum concentration of $0.04 \mathrm{~g} / \mathrm{L}$ and $0.14 \mathrm{~g} / \mathrm{L}$ when $5 \mathrm{~g} / \mathrm{L}$ lauric acid and $1 \mathrm{~g} / \mathrm{L}$ of methyl laurate was used as the substrate, respectively. When the bioconversion was continued to the fifth day, 3DA concentration detected in the system decreased. Moreover, both substrates concentration reached their lowest point on the fourth day (Figure 2), while cell concentration still increased until the end of bioconversion phase of 5 days (Figure 3). Taken together, these suggest that after the fourth day, the produced 3DA was subsequently utilized by $C$. tropicalis as the carbon source via $\beta$-oxidation pathway, as 3DA is an intermediate product in this metabolism pathway (Bogaert, 2011; Kester \& Foster, 1962). This also shows that during the bioconversion phase, the substrate itself is used as the carbon source for biomass growth. Therefore, the optimum duration for bioconversion phase is 4 days long.

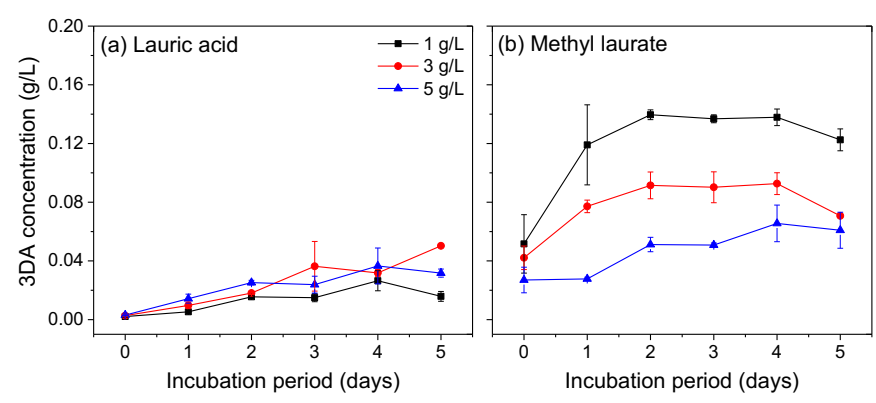

Fig. 3 3DA concentration profile during the bioconversion phase for (a) lauric acid and (b) methyl laurate. Error bars indicate standard error between replicates $(n=2)$.

Increasing lauric acid concentration from $1 \mathrm{~g} / \mathrm{L}$ to $3 \mathrm{~g} / \mathrm{L}$ or $5 \mathrm{~g} / \mathrm{L}$ barely resulted in any difference of produced 3DA concentration. On the other hand, increasing methyl laurate concentration reduced the overall 3DA concentration, especially on the fourth day. During methyl laurate conversion into 3DA, lauric acid was produced as the first intermediate, where methyl laurate concentration of $1 \mathrm{~g} / \mathrm{L}, 3 \mathrm{~g} / \mathrm{L}$, and 5 $\mathrm{g} / \mathrm{L}$ (soluble substrate concentration of $0.89 \mathrm{~g} / \mathrm{L}, 1.52 \mathrm{~g} / \mathrm{L}$, and $1.89 \mathrm{~g} / \mathrm{L}$ ) produced $0.89 \mathrm{~g} / \mathrm{L}, 1.52 \mathrm{~g} / \mathrm{L}$, and $1.89 \mathrm{~g} / \mathrm{L}$ of lauric acid, respectively.
These values already exceeded the minimum inhibitory concentration of lauric acid of $0.5 \mathrm{~g} / \mathrm{L}$ (Kabara, 1984). Therefore, it is highly likely that the reduction of 3DA at higher methyl laurate concentration was caused by this lauric acid inhibition.

Based on the maximum 3DA concentration obtained on the fourth day of bioconversion phase, the utilization of methyl laurate as the substrate resulted in higher 3DA yield $(9.3 \%$ when $1 \mathrm{~g} / \mathrm{L}$ was added) compared to lauric acid (maximum yield of $2.4 \%$ when $1 \mathrm{~g} / \mathrm{L}$ was added). Both systems showed that the increase in substrate concentrations have negative effects on 3DA yield, as lower 3DA yields were obtained at higher substrate concentrations. It was presumed that the aforementioned lauric acid inhibition on 3DA production caused this phenomenon. Similar result was observed when soluble substrate concentrations were used as the basis. However, lauric acid produced more 3DA (24.7\% when $1 \mathrm{~g} / \mathrm{L}$ was added) compared to methyl laurate (14.4\% when $1 \mathrm{~g} / \mathrm{L}$ was added) when the concentration detected from the system were used as the basis. The maximum 3DA yield obtained in this research is only $\sim 20 \%$ of the theoretically possible yield $(\sim 1.07-$ $1.15 \mathrm{~g}$-product/g-substrate, which is equimolar to the substrate used). Such low yield of 3DA acquired in here could be triggered by the strain type used in this research, which is a wild-type strain. A wild-type strain C. tropicalis is only capable of producing small amount of 3DA (Akhmalina et al., 2018) because the $\beta$-oxidation pathway is more prevalent, causing the $C$. tropicalis to produce more cell biomass compared to 3DA. When mutated of genetically engineered $C$. tropicalis was used, the maximum 3DA yield could increase to $80 \%$ as reported before (Green et al., 2000; Funk et al., 2017). Genetic engineering for improvement of certain metabolic products synthesis are commonly done in various other cases (Revuelta et al., 2016). The addition of $\beta$-oxidation pathway inhibitor such as acrylic acid is also feasible to improve 3DA productivity (Funk et al., 2017).
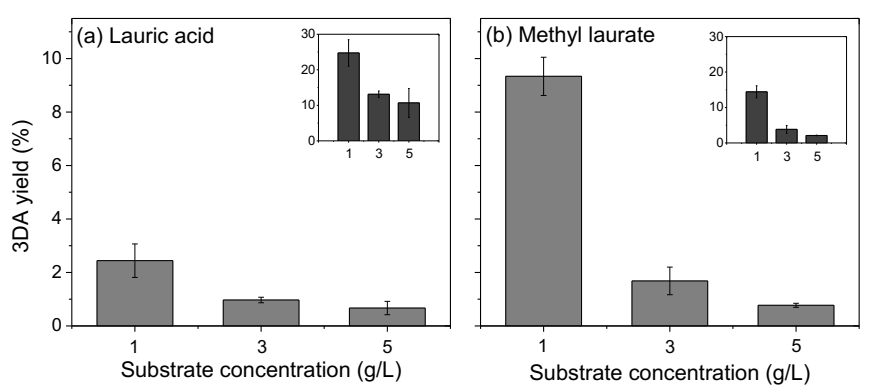

Fig. 4 3DA yield at the fourth day of bioconversion phase of (a) lauric acid based on added substrate concentration and soluble substrate concentration (inset) and (b) methyl laurate based on added substrate concentrate and soluble substrate concentration (inset). Yield is given in $\%$ g-product/g-substrate.

\section{CONCLUSION}

Herein, the potential of 3DA production from lauric acid and methyl laurate was successfully studied using wild-strain C. tropicalis obtained natively from Indonesia. $C$. tropicalis was able to be utilized in the presence of substrates as the carbon source, as shown by the increasing cell concentration and subsequent decreasing substrate concentration. The event was consequently followed by the production of 3DA, reaching the maximum value when the bioconversion stage was performed for 4 days. Prolonged bioconversion stage demonstrated a decrease in 3DA production and an increased cell concentration, indicating that the produced 3DA was subsequently used as a carbon source for cell growth via $\beta$-oxidation. Ultimately, the addition of methyl laurate showed higher concentration of generated 3DA, partly due to higher concentration of soluble methyl laurate compared to lauric acid. The highest 3DA yield was obtained when low concentration of methyl laurate $(1 \mathrm{~g} / \mathrm{L})$ was used. In conclusion, this research highlights the potential of commercial 3DA production by fermentation technology using wild-strain C. tropicalis. 


\section{ACKNOWLEDGEMENT}

This research is supported by KRIBB (Korean Research Institute of Bioscience and Biotechnology), Daejeon, Korea.

\section{REFERENCES}

Akmalina, R., Purwadi, R., Sitompul, J. 2018, Bioconversion studies of methyl laurate to dodecanedioic acid using a wild-type of Candida tropicalis, MATEC Web of Conferences, 156, 1001.

Campo, D. E. L. Javier, F., Pascual, M., Xavier, F. 2011, European patent application I(19), 1-27.

Cao, W., Li, H., Luo, J., Yin, J., Wan, Y. 2017, High-level productivity of $\alpha, \omega-$ dodecanedioic acid with a newly isolated Candida viswanathii strain, Journal of Industrial Microbiology and Biotechnology, 4(8), 1191-1202.

Chan, E. -C., Kuo, J., 1997b, Biotransformation of dicarboxylic acid by immobilized Cryptococcus cells. Enzyme and Microbial Technology, 20(8), 585-589.

Chan, E.-C., Cheng, C. -S., Hsu, Y. -H. 1997a, Continuous production of dicarboxylic acid by immobilized Pseudomonas aeruginosa cells, Journal of Fermentation and Bioengineering, 83(2), 157-160.

Feng, J., Zeng, Y., Ma, C., Cai, X., Zhang, Q., Tong, M., Yu, B., Xu, P., 2006, The surfactant Tween 80 enhances biodesulfurization, Applied and Environmental Microbiology, 72(11), 7390-7393.

Funk, I., Rimmel, N., Schorsch, C., Sieber, V., Schmid, J. 2017, Production of dodecanedioic acid via biotransformation of low-cost plant-oil derivatives using Candida tropicalis. Journal of Industrial Microbiology and Biotechnology, 1-12.

Gmünder, F. K., Kgppeli, O., Fiechter, A. 1981, Chemostat studies on the assimilation of hexadecane by the yeast Candida tropicalis, Applied Microbiology and Biotechnology, 12, 135-142.

Green, K. D., Turner, M. K., Woodley, J. M. 2000, Candida cloacae oxidation of long-chain fatty acids to dioic acids, Enzyme and Microbial Technology, 27(3-5), 205-211.

Huf, S., Krugener, S., Hirth, T., Rupp, S., Zibek, S. 2011, Biotechnological synthesis of long-chain dicarboxylic acids as building blocks for polymers. European Journal of Lipid Science and Technology, 113(5), 548-561.

Kabara, J. J. 1984, Antimicrobial agents derived from fatty acids, Journal of the American Oil Chemists' Society, 61(2), 397-403.

Kester, A. S., Foster, J. W. 1962, Diterminal oxidation of long-chain alkanes by bacteria, Journal of Bacteriology, 85(4), 859-869.

Kroha, K. 2004, Industrial biotechnology provides opportunities for commercial production of new long-chain dibasic acids, INFORM - International News on Fats, Oils and Related Materials, 15(9), 568-571.

Lee, H., Sugiharto, Y. E. C., Lee, S., Park, G., Han, C., Jang, H., Jeon, W., Park, H., Ahn, J., Kang, K., Lee, H. 2017, Characterization of the newly isolated $\omega$-oxidizing yeast Candida sorbophila DS02 and its potential applications in long-chain dicarboxylic acid production, Applied Microbiology Biotechnology, 101(16), 6333-634.

Lee, S. Y., Zakry, F. A. A., Show, P. L. 2015, Optimisation of citric acid production from a novel strain of Aspergillus niger by submerged fermentation, Chemical Engineering Transactions, 45, 1501-1506.

Lozano-Martinez, P., Ledesma-Amaro, R., Revuelta, J. L. 2016, Engineering Ashbya gossypii for the production of ricinoleic and linoleic acid, Chemical Engineering Transactions, 49, 253-258.

Mobley, D. P. 1999, Biosynthesis of long-chain dicarboxylic acid monomers from renewable resources biosynthesis of long-chain dicarboxylic acid monomers from renewable resources, Final Technical Report, GE Corporate Research and Development, Niskayuna, New York.

Slifkin, M. 2000, Tween 80 opacity test responses of various Candida species, Journal of Clinical Microbiology, 38(12), 4626-4628.

Van Bogaert, I. N. A., Groeneboer, S., Saerens, K., Soetaert, W. 2011, The role of cytochrome P450 monooxygenases in microbial fatty acid metabolism FEBS Journal, 278, 206-221. 